\section{Media Publikasi Promosi Kesehatan Indonesia The Indonesian Journal of Health Promotion}

\title{
Gambaran Tingkat Pengetahuan Masyarakat terhadap Pemilihan Obat Antiinflamasi Sebagai Upaya Pengobatan Sendiri di Kelurahan Kampung Satu Tarakan Tengah
}

\author{
The Description of Community Knowledge on The Selection of Anti-Inflammatory Drugs As \\ A Self-Medication Treatment In Kampung Satu Tarakan Tengah Village
}

\author{
${ }^{\left({ }^{*}\right)}$ Nur Ani, ${ }^{(2)}$ Lutfiana Kusumawati \\ Akademi Farmasi Tadulako Farma Palu \\ (*)any_cute89@yahoo.co.id \\ (*) Corresponding Author
}

\begin{abstract}
Abstrak
Swamedikasi adalah salah satu upaya yang sering dilakukan oleh seseorang dalam mengobati gejala penyakit yang dideritanya tanpa terlebih dahulu melakuan konsultasi ke dokter. Salah satu penyakit yang sering diobati secara swamedikasi adalah inflames (peradangan). Penelitian ini bertujuan untuk mengetahui tingkat pengetahuan masyarakat terhadap pemilihan obat antiinflamasi sebagai upaya pengobatan sendiri di Kelurahan Kampung Satu Tarakan, Penelitian ini termasuk penelitian deskriptif dengan menggunakan kuesioner yang ditujukan pada 100 responden yang dipilih berdasarkan teknik Purposive Sampling. Hasil penelitian menunjukkan bahwa tingkat pengetahuan masyarakat di Kelurahan Kampung Satu Kecamatan Tarakan Tengah tentang pemilihan obat antiinflamasi termasuk dalam kategori sangat rendah yaitu $\leq 50 \%$, namum pengetahuan mereka terhadap swamedikasi dikatakan baik karena $\geq 50 \%$.
\end{abstract}

Kata Kunci : Pengetahuan; swamedikasi inflamasi; antiinflamasi

\begin{abstract}
Self-medication is one effort often done by a person in treating the symptoms of illness without suffering first consultation to the doctor. One of the diseases that are often treated by self medication is inflammation. This study aims to determine the level of community knowledge of the selection of anti-inflammatory drugs as a treatment of their own in Kampung Satu SKIP Tarakan Tengah Village. This research includes descriptive research using questionnaire aimed at 100 respondents selected based on Purposive Sampling technique. The results showed that the level of community knowledge in KampungSatu Village, Tarakan Tengah on the selection of anti-inflammatory drugsvery low category under $\leq 50 \%$, and their knowledge of self-medicationare concluded in good result $\geq 50 \%$.
\end{abstract}

Keywords: Knowledge; self medication inflammatory: antiinflammatory 


\section{PENDAHULUAN}

Obat merupakan kebutuhan primer bagi yang sedang menderita sakit. Namun kadang-kadang masyarakat merasa bisa menjadi dokter bagi dirinya sendiri dengan cara mengobatinya sendiri tanpa memeriksakan diri terlebih dahulu kepada petugas kesehatan. Pengobatan sendiri (swamedikasi) merupakan salah satu bagian dari perawatan diri. Pengobatan sendiri diartikan dengan memilih dan menggunakan obat-obatan oleh seorang induvidu untuk mengobati penyakit yang diderita atau mengurangi gejalah tanpa pengawasan medis. Meskipun beberapa obat dianggap memiliki risiko yang kecil dan berguna untuk mengobati masalah kesehatan yang serius dan reaksi yang tidak tidak diinginkan (1). Pengobatan sendiri (swamedikasi) merupakan bagian dari upaya masyarakat menjaga kesehatannya sendiri. Pada pelaksanaannya, pengobatan sendiri dapat menjadi sumber masalah terkait obat (Drug related problem) akibat terbatasnya pengetahuan mengenai obat dan penggunaannya (2).

Swamedikasi bila tidak dilakukan secara benar justru menimbulkan masalah baru yaitu tidak sembuhnya penyakit karena adanya resistensi bakteri dan ketergantungan; munculnya penyakit baru karena efek samping obat antara lain seperti pendarahan sistem pencernaan, reaksi hipersensitif, serta meningkatnya kejadian keracunan. maka pada pelaksanaan swamedikasi, diprediksi akan banyak terjadi kesalahan penggunaan obat (medication error) yang disebabkan karena keterbatasan pengetahuan masyarakat akan obat dan penggunaannya (3). Obat merupakan semua zat kimia, hewani, maupun nabati yang dalam dosis layak dapat menyembuhkan, meringankan, atau mencegah penyakit.

Apabila dalam melakukan swamedikasi masyarakat tidak cukup mendapatkan informasi yang tepat mengenai indikasi obat, cara penggunaan, lama penggunaan, dan efek samping maka hal tersebut justru akan menimbulkan masalah kesehatan yang baru contohnya adalah parasetamol, salah satu penghilang rasa sakit yang paling banyak digunakan. Demikian menurut para ahli medis dari Norhwestern University Chicago menyebutkan, terlalu banyak mengonsumsi parasetamol dapat memicu kerusakan pada liver, serta timbulnya efek negatif pada bagian tubuh lain (4).

Berdasarkan hal tersebut maka peneliti tertarik untuk mendapatkan gambaran tingkat pengetahuan masyarakat terhadap pemilihan obat anti-inflamasi sebagai upaya pengobatan sendiri di Kelurahan Kampung Satu Skip Kecamatan Tarakan Tengah Kota Tarakan.

\section{METODE}

Penelitian yang dilakukan ini termasuk penelitian deskriptif dengan menggunakan data primer dan instrumen kuisioner penelitian, yaitu dengan melakukan pencarian fakta dengan interpretasi yang tepat. Lokasi penelitian dilaksanakan di daerah Kelurahan kampung Satu Skip Kecematan Tarakan Tengah Kota Tarakan. Sampel penelitian yang diambil berjumlah 100 responden. Pengambilan sampel pada penelitian ini menggunakan teknik Purposive Sampling, dimana dalam memilih sampel dari populasi berdasarkan pertimbangan dan karakteristik tertentu berdasarkan kriteria inklusi. ${ }^{5}$ Pengumpulan data dari responden dilakukan melalui kuesioner kepada responden yang telah dirancang sedemikian rupa agar diperoleh informasi yang diinginkan.

\section{HASIL}

Data hasil penelitian mengenai Gambaran Pengetahuan Masyarakat Kelurahan Kampung Satu Tarakan Tengah tentang pengobatan sendiri antiinflamasi diperoleh dari hasil jawaban kuesioner yang ditujukan kepada 100 orang responden yang dipilih secara purposive sampling. 
Berdasarkan data karakteristik responden pada tabel 1, menunjukkan bahwa jumlah responden perempuan lebih banyak yaitu 54 orang (54\%), sedangkan yang berjenis kelamin laki-laki sebanyak 46 responden (46\%). Tingkat pendidikan responden terdiri dari S1/S2 (18\%), D3 (4\%), SMA/SMK/SLTA (58\%), SMP (12\%), SD (3\%) dan tidak sekolah 5\%. Berdasarkan usia, responden yang berusia 17-25 tahun (30\%), 26-35 tahun (32\%), 36-45 tahun (19\%), 46-55 tahun (15\%), dan 56-65 tahun (4\%). Dilihat dari pekerjaan, meliputi buruh (9\%), ibu rumah tangga (24\%), mahasiswa (15\%), pegawai (23\%), swasta (21\%), dan pengangguran $(8 \%)$.

\section{PEMBAHASAN}

Salah satu faktor yang mempengaruhi swamedikasi adalah jenis kelamin, yaitu dalam hal menekan biaya obat yang dibeli (7). Pada umumnya, perempuan lebih memperhatikan biaya selain efektivitas obat yang digunakan serta menganggap penceggahan dan pengobatan mengunakan obat dianggap lebih efektif daripada laki-laki (8). Usia mempengaruhi swamedikasi yang dilakukan masyarakat dalam pengambilan keputusan terhadap pemilihan obat (7). Persepsi yang berbeda terkait swamedikasi dapat dibentuk oleh latar belakang pendidikan. Pendidikan tinggi mengajarkan seseorang untuk berfikir logis dan rasional tentang swamedikasi sehingga semakin berhati-hati dalam penggunaan obat untuk swamendikasi (9). Perkerjaan juga bisa mempengaruhi seseorang dalam melakukan swamedikasi. Berdasarkan hasil penelitaan yang telah dilakukan responden yang paling banyak yaitu ibu rumah tangga. Pekerjaan dapat mempengaruhi seseorang dalam melakukan swamedikasi yaitu mempengaruhi pola pikir seseorang sebelum memutuskan pemilihan obat yang akan digunakan untuk mengatasi keluhannya. Seseorang yang berkerja dibidang kesehatan akan mengambil keputusan yang lebih rasional terkait obat yang akan digunakaan karna memiliki pengetahuan yang lebih baik dalam melakukan swamedikasi dibandingkan dengan seseorang yang berkerja diluar bidang kesehatan (7).

Hasil presentase jawaban responden terhadap pengetahun tentang inflamasi, dapat dikatakan pengetahuan masyarakat tentang Inflamasi sangat rendah, karena skor rata-rata tertinggi adalah terdapat pada jawaban "Tidak Tahu" yaitu 113\%. Hal ini disebabkan karena kurangnya penyuluhan kesehatan dari petugas kesehatan. Pada indikator pertanyaan yang kedua peneliti membagi menjadi 2 indikator yaitu golongan Steroid dan Non Steroid hal ini bertujuan untuk mengetahui bagaimana tingkat pengetahuan masyarakat terhadap kedua golongan tersebut. Hasil jawaban responden pada kuesioner pemilihan obat antiinflamasi steroid dan non steroid, dapat disimpukan bahwa responden memiliki pengetahuan yang rendah tentang obat antiinflamasi, hal ini disebabkan karena jawaban responden pada jawaban "Tidak Tahu” diperoleh persentase 113\% dan 112\%.

Pengetahuan masyarakat di kelurahan Kampung Satu tentang Swamedikasi atau pengobatan sendiri munujukan bahwa banyak yang mengetahui di bandingkan tidak mengetahui. Di karenakan masyarakat sering melakukan swamedikasi, walaupun demikian penyuluhan dari pihak kesehatan juga harus di lakukan agar masyarakat tidak sembarang dalam memilih obat pada saat pengobatan sendiri.

Pengetahuan masyarakat tentang penggunaan antiinflamasi, kegunaan, efek samping serta golongan antiinflamasi yang dapat diperoleh dengan resep dokter mau pun yang dapat diperoleh secara/ bebas sangat rendah. Hal ini menyebabkan masyarakat tidak bijak menggunakan obat antiinflamasi yang tidak tepat indikasi, tidak tepat dosis, tidak mengetahui lama pemberian obat. Untuk itu, masyarakat perlu medapatkan perhatian ketika akan menjalani pengobatan antiinflamasi yaitu atas resep dokter dan juga atas petunjuk dokter atau medis. Dosis yang tertera serta aturan pakainya harus sesuai penjelasan dokter ataupun apoteker tempat membeli obat tersebut. Pemberian antiinflamasi dan jenis macam obat lainnya harus di minum sesuai takaran dan arahan dari dokter, apoteker dan pihak medis lainnya. 


\section{KESIMPULAN}

Berdasarkan hasil penelitian yang telah dilakukan, maka dapat disimpulan Gambaran tingkat pengetahuan masyarakat terhadap pemilihan obat antiinflamasi sebagai upaya pengobatan sendiri di kelurahan Kampung Satu Skip kecemata Tarakan Tengah dari Kategori inflamasi dan antiinfamasi didapatkan hasil rata-rata $\leq 50 \%$ (kurang baik) sedangkankan pada variabel swamedikasi 92\% (Baik) di sini swamediksi memiliki poin tertinggi dikarenakan masyarakat sering melakukan swamedikasi. Berdasarkan kesimpulan pada penelitian ini, maka diharapkan adanya sosialisasi atau penyuluhan kepada masyarakat tentang pemilihan obat antiinflamasi sebagai upaya pengobatan sendiri oleh masyarakat kelurahan Kampung Satu Kota Tarakan.

\section{DAFTAR PUSTAKA}

1. Alfa,I. Persepsi Pasien Terhadap Pelayanan Swamedikasi oleh Apoteker di beberapa Apoteker Wilayah Surabaya Selatan. 2015;4(2):2

2. Harahap NA, Khaerunnisa, Tanuwijaya J. Tingkat Pengetahuan Pasien dan Rasionalitas Swamedikasi di Tiga Apotek Kota Penyabungan. Jurnal Sains Farmasi dan Klinis. 2017;3(2):186-192

3. Galato D, Galafassi LM, Alano GM, Trauthman SC. Responsible Self- Medication: Review Of The Process Of Pharmaceutical Attendance. Brazilian Journal of Pharmaceutical Sciencesvol. 2009;45(4):626-632

4. Tjay dan Rahardja. Obat-obat penting khasiat pengunaan dan efek sampingnya. Jakarta: Elex Medika komputindo; 2007

5. Suharsaputra U. Metode penelitian kuantitatif, kualitatif, dan tindakan. Bandung:Refika Aditama; 2014

6. Riyanto dan Budiman. Kapita Selekta Kuesioner Pengetahuan danSikap Dalam Penelitian Kesehatan. Jakarta: Salemba Medika; 2017

7. Rikomah SE. Farmasi Klinik. Edisi 1. Yogyakarta: Deepublish; 2016

8. Luvkovic et al. Self Medication practices and Risk factor for self medication among medical studens in Belgrad, Serbia. Journal PLoSONE. 2014;(12)

9. Utaminigrum, W. Lestari J.e dan Kusuma, A.m. 2015. Pengaruh Faktor-Faktor Sosiodemografi terhadap Rasionalitas Penggunaan Obat dalam Pengobatan Sendiri Pada Pasien Program Pengolahan Penyakit Kronis (Prolantis). Jurnal Farma Sains. 2015;2(6):285-288 


\section{LAMPIRAN}

Tabel 1. Data Karakteristik Responden

\begin{tabular}{|c|c|c|}
\hline \multirow{2}{*}{ Karakteristik } & \multicolumn{2}{|c|}{ Informan } \\
\hline & Jumlah & Persentase \\
\hline $\begin{array}{l}\text { Jenis Kelamin } \\
\qquad \begin{array}{l}\text { Laki-laki } \\
\text { Perempuan }\end{array}\end{array}$ & $\begin{array}{l}46 \\
54\end{array}$ & $\begin{array}{l}46 \% \\
54 \%\end{array}$ \\
\hline $\begin{array}{l}\text { 2. Pendidikan } \\
\text { S1/ S2 } \\
\text { D3 } \\
\text { SMA/SMK/SLTA } \\
\text { SMP } \\
\text { SD } \\
\text { Tidak sekolah } \\
\end{array}$ & $\begin{array}{c}18 \\
4 \\
58 \\
12 \\
3 \\
5\end{array}$ & $\begin{array}{c}18 \% \\
4 \% \\
58 \% \\
12 \% \\
3 \% \\
5 \%\end{array}$ \\
\hline $\begin{array}{l}\text { 3. Usia } \\
\begin{array}{r}17-25 \\
26-35 \\
36-45 \\
46-55 \\
56-65\end{array}\end{array}$ & $\begin{array}{c}30 \\
32 \\
19 \\
15 \\
4\end{array}$ & $\begin{array}{c}30 \% \\
32 \% \\
19 \% \\
15 \% \\
4 \%\end{array}$ \\
\hline $\begin{array}{l}\text { Buruh } \\
\text { Ibu Rumah Tangga } \\
\text { Mahasiswa } \\
\text { Pegawai } \\
\text { Swasta } \\
\text { Pengganguran }\end{array}$ & $\begin{array}{c}9 \\
24 \\
15 \\
23 \\
21 \\
8\end{array}$ & $\begin{array}{c}9 \% \\
24 \% \\
15 \% \\
23 \% \\
21 \% \\
8 \%\end{array}$ \\
\hline
\end{tabular}

